\title{
A new iterative method for equilibrium problems and fixed point problems for infinite family of nonself strictly pseudocontractive mappings
}

Jong Kyu Kim" and Nguyen Buong ${ }^{2}$

"Correspondence:

jongkyuk@kyungnam.ac.kr

'Department of Mathematics,

Kyungnam University, Changwon,

Gyeongnam 631-701, Korea

Full list of author information is

available at the end of the article

\begin{abstract}
The purpose of this paper is to present an iterative method for finding a common element of the set of solutions for an equilibrium problem and the set of common fixed points for a countably infinite family of nonself $\lambda_{i}$-strictly pseudocontractive mappings $\left\{T_{i}\right\}_{i=1}^{\infty}$ from a closed convex subset $\mathrm{C}$ into a Hilbert space $H$.

MSC: $47 \mathrm{H} 17 ; 47 \mathrm{H} 20$
\end{abstract}

Keywords: regularization; hemicontinuous; lower semicontinuous convex functional; fixed points

\section{Introduction and preliminaries}

Let $H$ be a real Hilbert space with the inner product $\langle\cdot, \cdot\rangle$ and the norm $\|\cdot\|$, respectively. Let $C$ be a nonempty closed convex subset of $H$, and let $G: C \times C \rightarrow(-\infty,+\infty)$ be a bifunction. The equilibrium problem for $G$ is to find $u^{*} \in C$ such that

$$
G\left(u^{*}, v\right) \geq 0, \quad \forall v \in C .
$$

The set of solutions of (1.1) is denoted by $\operatorname{EP}(G)$. The equilibrium problem (1.1) includes as special cases numerous problems in physics, optimization, economics, transportation, and engineering.

Assume that the bifunction $G$ satisfies the following standard properties.

Assumption A Let $G: C \times C \rightarrow(-\infty,+\infty)$ be a bifunction satisfying conditions (A1)(A4).

(A1) $G(u, u)=0, \forall u \in C$;

(A2) $G(u, v)+G(v, u) \leq 0, \forall(u, v) \in C \times C$;

(A3) For each $u \in C, G(u, \cdot): C \rightarrow(-\infty,+\infty)$ is lower semicontinuous and convex;

(A4) $\lim \sup _{t \rightarrow+0} G((1-t) u+t z, v) \leq G(u, v), \forall(u, z, v) \in C \times C \times C$.

Recall that a mapping $T$ in $H$ is said to be $\lambda$-strictly pseudocontractive in the terminology of Browder and Petryshyn [1], if there exists a constant $0 \leq \lambda<1$ such that

$$
\|T x-T y\|^{2} \leq\|x-y\|^{2}+\lambda\|(I-T) x-(I-T) y\|^{2}
$$

@2013 Kim and Buong; licensee Springer. This is an Open Access article distributed under the terms of the Creative Commons Attribution License (http://creativecommons.org/licenses/by/2.0), which permits unrestricted use, distribution, and reproduction in any medium, provided the original work is properly cited. 
for all $x, y \in D(T)$, the domain of $T$, where $I$ is the identity operator in $H$. Clearly, when $\lambda=0, T$ is nonexpansive, i.e.,

$$
\|T(x)-T(y)\| \leq\|x-y\| .
$$

It means that the class of $\lambda$-strictly pseudocontractive mappings strictly includes the class of nonexpansive mappings.

A single-valued mapping $A$ in $H$ is said to be monotone, if

$$
\langle A(x)-A(y), x-y\rangle \geq 0, \quad \forall x, y \in D(A),
$$

and $\lambda$-inverse strongly monotone, if there exists a positive constant $\lambda$ such that

$$
\langle A(x)-A(y), x-y\rangle \geq \lambda\|A(x)-A(y)\|^{2}, \quad \forall x, y \in D(A) .
$$

Therefore, any $\lambda$-inverse strongly monotone mapping is monotone and Lipschitz continuous with the Lipschitz constant $L_{A}=1 / \lambda$. It is well known [2] that if $T$ is a nonexpansive mapping, then $I-T$ is (1/2)-inverse strongly monotone. It is easy to verify that if $T$ is $\lambda$ strictly pseudocontractive, then it is $(1-\lambda) / 2$-inverse strongly monotone. Hence, $I-T$ is Lipschitz continuous with the Lipschitz constant $L=2 /(1-\lambda)$.

Let $\left\{T_{i}\right\}_{i=1}^{\infty}$ be a countably infinite family of nonself $\lambda_{i}$-strictly pseudocontractive mappings from $C$ into $H$ with the set of fixed points $F\left(T_{i}\right)$ (i.e., $F\left(T_{i}\right)=\left\{x \in C: x=T_{i} x\right\}$ ). Set $\mathcal{F}:=\bigcap_{i=1}^{\infty} F\left(T_{i}\right)$. Assume that

$$
\mathcal{S}:=\mathcal{F} \cap \operatorname{EP}(G) \neq \emptyset
$$

The problem studied in this paper is to find an element

$$
u^{*} \in \mathcal{S} \text {. }
$$

If $T_{i} \equiv I, i \geq 1$, then problem (1.2) is reduced to (1.1) and shown in [3] and [4] to cover monotone inclusion problems, saddle point problems, variational inequality problems, minimization problems, the Nash equilibria in noncooperative games, vector equilibrium problems, as well as certain fixed point problems (see also [5]). For finding approximative solutions of (1.1), there exist several approaches: the regularization approach [6-10], the gap-function approach [8,11-13], and iterative procedure approach [14-30].

In the case that $G \equiv 0$ and $T_{i}=I, i>1,(1.2)$ is a problem of finding a fixed point for a $\lambda$-strictly pseudocontractive mapping in $C$ (see [31]).

In the case that $G \equiv 0$ and $T_{i}=I, i>N>1,(1.2)$ is a problem of finding a common fixed point for a finite family of $\lambda_{i}$-strictly pseudocontractive mappings $T_{i}$ in $C$ studied in [32], where the following algorithm is constructed:

Let $x_{0} \in C$ and $\left\{\alpha_{n}\right\},\left\{\beta_{n}\right\},\left\{\gamma_{n}\right\}$ be three sequences in $[0,1]$ satisfying $\alpha_{n}+\beta_{n}+\gamma_{n}=1$ for all $n \geq 1$, and let $\left\{u_{n}\right\}$ be a sequence in $C$. Then the sequence $\left\{x_{n}\right\}$ generated by

$$
x_{n}=\alpha_{n} x_{n-1}+\beta_{n} T_{n} x_{n}+\gamma_{n} u_{n}
$$


where $T_{n}=T_{n \bmod N}$, is called the implicit iteration process with mean errors for a finite family of strictly pseudocontractive mappings $\left\{T_{i}\right\}_{i=1}^{N}$. The sequence $\left\{x_{n}\right\}$ converges weakly to a common fixed point of the maps $\left\{T_{i}\right\}_{i=1}^{N}$.

If $T_{i}=I, i>1$, then (1.2) is a problem of finding a fixed point for a $\lambda$-strictly pseudocontractive mapping in $C$, which is an equilibrium point for $G$ (see [33]).

Theorem 1.1 [33] Let $C$ be a nonempty closed convex subset of a Hilbert space H. Let $G$ be a bifunction from $C \times C$ to $(-\infty,+\infty)$ satisfying (A1)-(A4), and let $S$ be a nonexpansive mapping of $C$ into $H$ such that

$F(S) \cap \operatorname{EP}(G) \neq \emptyset$.

Letf be a contraction of $H$ into itself, and let $\left\{x_{n}\right\}$ and $\left\{u_{n}\right\}$ be sequences generated by $x_{1} \in H$ and

$$
\left\{\begin{array}{l}
G\left(u_{n}, y\right)+\frac{1}{r_{n}}\left\langle y-u_{n}, u_{n}-x_{n}\right\rangle \geq 0, \quad \forall y \in C, \\
x_{n+1}=\alpha_{n} f\left(x_{n}\right)+\left(1-\alpha_{n}\right) S u_{n}
\end{array}\right.
$$

for all $n \geq 0$, where $\left\{\alpha_{n}\right\} \subset[0,1]$ and $\left\{r_{n}\right\} \subset(0, \infty)$ satisfy

$$
\begin{array}{ll}
\lim _{n \rightarrow \infty} \alpha_{n}=0, & \sum_{n=1}^{\infty} \alpha_{n}=\infty, \quad \sum_{n=1}^{\infty}\left|\alpha_{n+1}-\alpha_{n}\right|<\infty, \\
\liminf _{n \rightarrow \infty} r_{n}>0, & \sum_{n=1}^{\infty}\left|r_{n+1}-r_{n}\right|<\infty .
\end{array}
$$

Then $\left\{x_{n}\right\}$ and $\left\{u_{n}\right\}$ converge strongly to $z \in F(S) \cap \operatorname{EP}(G)$, where $z=P_{F(S) \cap \operatorname{EP}(G)} f(z)$.

If $T_{i}=I, i>N>1$, then (1.2) is a problem of finding a common fixed point for a finite family of $\lambda_{i}$-strictly pseudocontractive mapping $T_{i}$ from $C$ into $H$, which is an equilibrium point for $G$. We have constructed regularization algorithms (see $[10,19,29])$. First algorithm is defined as follows. The regularization solution $u_{\alpha}$ is an element being a solution for the single equilibrium problem

$$
\begin{cases}G_{\alpha}\left(u_{\alpha}, v\right) \geq 0 & \forall v \in C, u_{\alpha} \in C, \\ G_{\alpha}(u, v):=\sum_{i=0}^{N} \alpha^{\mu_{i}} G_{i}(u, v)+\alpha\langle u, v-u\rangle, & \alpha>0, \\ G_{0}(u, v)=G(u, v), \quad G_{i}(u, v)=\left\langle A_{i}(u), v-u\right\rangle, & i=1, \ldots, N, \\ \mu_{0}=0<\mu_{i}<\mu_{i+1}<1, & i=2, \ldots, N-1,\end{cases}
$$

where $\alpha$ is the regularization parameter.

Theorem 1.2 [19] For each $\alpha>0$, problem (1.4) has a unique solution $u_{\alpha}$ such that

(i) $\lim _{\alpha \rightarrow+0} u_{\alpha}=u^{*}, u^{*} \in \mathcal{S}$.

(ii) $\left\|u^{*}\right\| \leq\|y\|, \forall y \in \mathcal{S}$.

(iii) $\left\|u_{\alpha}-u_{\beta}\right\| \leq\left(\left\|u^{*}\right\|+d N\right) \frac{|\alpha-\beta|}{\alpha}, \alpha, \beta>0$, where $d$ is a positive constant. 
In the second algorithm, the regularization solution is defined on the base of the inertial proximal point algorithm proposed by Alvarez and Attouch [34], where the sequence $\left\{z_{n}\right\}$ is defined by an equilibrium problem

$$
\begin{aligned}
\tilde{c}_{n} & \left(\sum_{i=0}^{N} \alpha_{n}^{\mu_{i}} F_{i}\left(z_{n+1}, v\right)+\alpha_{n}\left\langle z_{n+1}, v-z_{n+1}\right\rangle\right)+\left\langle z_{n+1}-z_{n}, v-z_{n+1}\right\rangle \\
& -\gamma_{n}\left\langle z_{n}-z_{n-1}, v-z_{n+1}\right\rangle \geq 0 \quad \forall v \in C, z_{0}, z_{1} \in C,
\end{aligned}
$$

and $\left\{\tilde{c}_{n}\right\}$ and $\left\{\gamma_{n}\right\}$ are the sequences of positive numbers.

Theorem 1.3 [19] Assume that the parameters $\tilde{c}_{n}, \gamma_{n}$ and $\alpha_{n}$ are chosen such that

(i) $0<c_{0}<\tilde{c}_{n}, 0 \leq \gamma_{n}<\gamma_{0}$,

(ii) $\sum_{n=1}^{\infty} b_{n}=+\infty, b_{n}=\tilde{c}_{n} \alpha_{n} /\left(1+\tilde{c}_{n} \alpha_{n}\right)$,

(iii) $\sum_{n=1}^{\infty} \gamma_{n} b_{n}^{-1}\left\|z_{n}-z_{n-1}\right\|<+\infty$,

(iv) $\lim _{n \rightarrow \infty} \alpha_{n}=0, \lim _{n \rightarrow \infty} \frac{\left|\alpha_{n}-\alpha_{n+1}\right|}{\alpha_{n} b_{n}}=0$.

Then the sequence $\left\{z_{n}\right\}$ converges strongly to the element $u^{*}$, as $n \rightarrow+\infty$.

In the case that $G \equiv 0$, Maingé [35] considered the following iteration method:

$$
x_{n+1}=\alpha_{n} D x_{n}+\sum_{i \geq 1} w_{i, n} T_{i} x_{n}, \quad n \geq 0,
$$

where $D: C \rightarrow C$ is a given contraction with constant $\rho \in[0,1), x_{0} \in C$ is a starting point, $\left\{\alpha_{n}\right\} \subset(0,1), w_{i, n} \geq 0$ for all $i \geq 1$ and $\sum_{i \geq 1} w_{i, n}=1-\alpha_{n}$ with the following conditions:

C1. $\sum_{n=0}^{\infty} \alpha_{n}=\infty$.

C2. For all $i \in \mathcal{N}_{I}:=\left\{i: T_{i} \neq I\right\}$,

(a) $\frac{1}{w_{i, n}}\left|1-\frac{\alpha_{n-1}}{\alpha_{n}}\right| \rightarrow 0$, or $\sum_{n} \frac{1}{w_{i, n}}\left|\alpha_{n}-\alpha_{n-1}\right|<\infty$,

(b) $\frac{1}{\alpha_{n}}\left|\frac{1}{w_{i, n}}-\frac{1}{w_{i, n-1}}\right| \rightarrow 0$, or $\sum_{n}\left|\frac{1}{w_{i, n}}-\frac{1}{w_{i, n-1}}\right|<\infty$,

(c) $\frac{1}{w_{i, n} \alpha_{n}} \sum_{k \geq 0}\left|w_{k, n}-w_{k, n-1}\right| \rightarrow 0$, or $\sum_{n} \frac{1}{w_{i, n}} \sum_{k \geq 0}\left|w_{k, n}-w_{k, n-1}\right|<\infty$.

C3. $\frac{\alpha_{n}}{w_{i, n}} \rightarrow 0$ for all $i \in \mathcal{N}_{I}$.

Then the sequence $\left\{x_{n}\right\}$ given by (1.5) converges strongly to $\bar{x}$ the unique fixed point of $P_{\mathcal{F}} o D$, where $P_{\mathcal{F}}$ is the metric projection from $H$ onto $\mathcal{F}$.

For solving (1.2), Ceng and Yao [36] proposed the following algorithm:

Let $x_{1} \in H$ be an arbitrary element and

$$
\left\{\begin{array}{l}
G\left(u_{n}, v\right)+\frac{1}{r_{n}}\left\langle u_{n}-x_{n}, v-u_{n}\right\rangle, \quad \forall v \in C, \\
y_{n}=\left(1-\gamma_{n}\right) x_{n}+\gamma_{n} W_{n} u_{n}, \\
x_{n+1}=\left(1-\alpha_{n}-\beta_{n}\right) x_{n}+\alpha_{n} f\left(y_{n}\right)+\beta_{n} W_{n} y_{n},
\end{array}\right.
$$


where $\left\{\alpha_{n}\right\},\left\{\beta_{n}\right\}$, and $\left\{\gamma_{n}\right\}$ are three sequences in $(0,1)$ such that $\alpha_{n}+\beta_{n} \leq 1$, and the mapping $W_{n}$ is defined by

$$
\left\{\begin{array}{l}
U_{n, n+1}=I, \\
U_{n, n}=\lambda_{n} T_{n} U_{n, n+1}+\left(1-\lambda_{n}\right) I, \\
U_{n, n-1}=\lambda_{n-1} T_{n-1} U_{n, n}+\left(1-\lambda_{n-1}\right) I, \\
\cdots \\
U_{n, k}=\lambda_{k} T_{n} U_{n, k+1}+\left(1-\lambda_{k}\right) I, \\
U_{n, k-1}=\lambda_{k-1} T_{k-1} U_{n, k}+\left(1-\lambda_{k-1}\right) I, \\
\cdots \\
U_{n, 2}=\lambda_{2} T_{2} U_{n, 3}+\left(1-\lambda_{2}\right) I, \\
W_{n}=U_{n, 1}=\lambda_{1} T_{1} U_{n, 2}+\left(1-\lambda_{1}\right) I .
\end{array}\right.
$$

Theorem 1.4 [36] Let $C$ be a nonempty closed convex subset of a real Hilbert space H. Let $G: C \times C \rightarrow(-\infty,+\infty)$ be a bifunction satisfying (A1)-(A4), and let $\left\{T_{i}\right\}_{i=1}^{\infty}$ be a sequence of nonexpansive self-mappings on $C$ such that

$$
\mathcal{S}=\bigcap_{i=1}^{\infty} F\left(T_{i}\right) \cap \mathrm{EP}(G) \neq \emptyset .
$$

Suppose that $\left\{\alpha_{n}\right\},\left\{\beta_{n}\right\}$, and $\left\{\gamma_{n}\right\}$ are sequences in $(0,1)$ such that $\alpha_{n}+\beta_{n} \leq 1$, and $\left\{r_{n}\right\} \subset$ $(0, \infty)$ is a real sequence. Suppose that the following conditions are satisfied:

(i) $\lim _{n \rightarrow \infty} \alpha_{n}=0$ and $\sum_{n=0}^{\infty} \alpha_{n}=\infty$;

(ii) $0<\liminf _{n \rightarrow \infty} \beta_{n} \leq \limsup _{n \rightarrow \infty} \beta_{n}<1$;

(iii) $0<\liminf _{n \rightarrow \infty} \gamma_{n} \leq \limsup _{n \rightarrow \infty} \gamma_{n}<1$ and $\lim _{n \rightarrow \infty}\left|\gamma_{n+1}-\gamma_{n}\right|=0$;

(iv) $0<\liminf _{n \rightarrow \infty} r_{n}$ and $\lim _{n \rightarrow \infty}\left|r_{n+1}-r_{n}\right|=0$.

Let $f$ be a contraction of $C$ into itself and given $x_{0} \in C$. Then the sequences $\left\{x_{n}\right\}$ and $\left\{u_{n}\right\}$ generated by (1.6), where $\left\{\lambda_{n}\right\}$ is a sequence in $(0, b]$ for some $b \in(0,1)$, converge strongly to $x^{*} \in \bigcap_{i=1}^{\infty} F\left(T_{i}\right) \cap \mathrm{EP}(G)$, where $x^{*}=P_{\bigcap_{i=1}^{\infty} F\left(T_{i}\right) \cap \mathrm{EP}(G)} f\left(x^{*}\right)$.

\section{Main results}

In this section, for solving problem (1.2), we present a new iterative method.

Let $z_{0}$ be an arbitrary element in a Hilbert space $H$, the sequence of iterations $\left\{z_{n}\right\}$ is defined by finding $u_{n} \in C$ such that

$$
\left\{\begin{array}{l}
G\left(u_{n}, y\right)+\left\langle u_{n}-z_{n}, y-u_{n}\right\rangle \geq 0, \quad \forall y \in C, \\
z_{n+1}=P_{C}\left(z_{n}-\beta_{n}\left[z_{n}-u_{n}+\sum_{i=1}^{\infty} \gamma_{i} A_{i}\left(z_{n}\right)+\alpha_{n} z_{n}\right]\right) \\
\quad=P_{C}\left(z_{n}-\beta_{n}\left[\sum_{i=1}^{\infty} \gamma_{i} A_{i}\left(z_{n}\right)+\left(1+\alpha_{n}\right) z_{n}-u_{n}\right]\right), \quad n \geq 0,
\end{array}\right.
$$

where $P_{C}$ is the metric projection of $H$ onto $C$, and $\left\{\alpha_{n}\right\},\left\{\beta_{n}\right\}$, and $\left\{\gamma_{i}\right\}$ are three sequences of positive numbers such that

$$
\sum_{i=1}^{\infty} \gamma_{i} \frac{2}{1-\lambda_{i}}=\gamma<\infty
$$


Also, we construct a regularization solution $u_{\alpha}$ for (1.2) by solving the following variational inequality problem: find $u_{\alpha} \in C$ such that

$$
\begin{cases}\left\langle A_{0}\left(u_{\alpha}\right)+\sum_{i=1}^{\infty} \gamma_{i} A_{i}\left(u_{\alpha}\right)+\alpha u_{\alpha}, v-u_{\alpha}\right\rangle \geq 0, & \forall v \in C, \\ A_{i}=I-T_{i}, & i \geq 0,\end{cases}
$$

where $T_{0}(x)=\{z \in C: G(z, v)+\langle z-x, v-z\rangle \geq 0 \forall v \in C\},\left\{\gamma_{i}\right\}$ is a sequence of positive numbers satisfying $(2,2)$, and $\alpha$ is a small regularization parameter tending to zero.

We need the following important lemmas for the proof of our main results.

Lemma 2.1 [7] Let $C$ be a nonempty closed convex subset of a Hilbert space $H$, and let $G$ be a bifunction of $C \times C$ into $(-\infty,+\infty)$ satisfying (A1)-(A4). Let $r>0$ and $x \in H$. Then there exists $z \in C$ such that

$$
G(z, v)+\frac{1}{r}\langle z-x, v-z\rangle \geq 0, \quad \forall v \in C .
$$

Lemma 2.2 [7] Assume that $G: C \times C \rightarrow(-\infty,+\infty)$ satisfies conditions (A1)-(A4). For $r>0$ and $x \in H$, define a mapping $T_{r}: H \rightarrow C$ as follows:

$$
T_{r}(x)=\left\{z \in C: G(z, v)+\frac{1}{r}\langle z-x, v-z\rangle \geq 0 \forall v \in C\right\} .
$$

Then the following statements hold:

(i) $T_{r}$ is single-valued;

(ii) $T_{r}$ is firmly nonexpansive, i.e., for any $x, y \in H$,

$$
\left\|T_{r}(x)-T_{r}(y)\right\|^{2} \leq\left\langle T_{r}(x)-T_{r}(y), x-y\right\rangle
$$

(iii) $F\left(T_{r}\right)=\operatorname{EP}(G)$;

(iv) $\mathrm{EP}(G)$ is closed and convex.

It is easy to see that $T_{r}$ is a nonexpansive mapping.

Lemma 2.3 [37] Let $\left\{a_{n}\right\},\left\{b_{n}\right\}$, and $\left\{c_{n}\right\}$ be the sequences of positive numbers satisfying the conditions:

(i) $a_{n+1} \leq\left(1-b_{n}\right) a_{n}+c_{n}, b_{n}<1$,

(ii) $\sum_{n=0}^{\infty} b_{n}=+\infty, \lim _{n \rightarrow+\infty} \frac{c_{n}}{b_{n}}=0$.

Then $\lim _{n \rightarrow+\infty} a_{n}=0$.

Lemma $2.4[38,39]$ Assume that $T$ is a $\lambda$-strictly pseudocontractive mapping of a closed convex subset $C$ of a Hilbert space $H$. Then $I-T$ is demiclosed at zero; that is, whenever $\left\{x_{n}\right\}$ is a sequence in $C$ weakly converging to some $x \in C$, and the sequence $\left\{(I-T)\left(x_{n}\right)\right\}$ strongly converges to zero, it follows that $(I-T)(x)=0$.

Now, we are in a position to introduce and prove the main results. 
Theorem 2.5 Let $C$ be a nonempty closed convex subset of a real Hilbert space H. Let $G: C \times C \rightarrow(-\infty,+\infty)$ be a bifunction satisfying (A1)-(A4), and let $\left\{T_{i}\right\}_{i=1}^{\infty}$ be a sequence of nonself $\lambda_{i}$-strictly pseudocontractive mappings from $C$ into $H$ such that

$$
\mathcal{S}=\bigcap_{i=1}^{\infty} F\left(T_{i}\right) \cap \mathrm{EP}(G) \neq \emptyset .
$$

Assume that $\left\{\gamma_{i}\right\}$ satisfies condition (2.2). Then for each $\alpha>0$, problem (2.3) has a unique solution $u_{\alpha}$ such that

(i) $\lim _{\alpha \rightarrow 0} u_{\alpha}=u^{*}, u^{*} \in \mathcal{S}$ and $\left\|u^{*}\right\| \leq\|y\|, \forall y \in \mathcal{S}$,

(ii) $\left\|u_{\alpha}-u_{\beta}\right\| \leq \frac{|\alpha-\beta|}{\alpha}\left\|u^{*}\right\|$.

Proof First, we prove that problem (2.3) has a unique solution. Set

$$
A:=\sum_{i=1}^{\infty} \gamma_{i} A_{i}
$$

Let $x^{*}$ be a common fixed point of $\left\{T_{i}\right\}_{i \geq 1}$. Since

$$
\gamma_{i}\left\|A_{i}(x)\right\| \leq \gamma_{i}\left\|A_{i}(x)-A_{i}\left(x^{*}\right)\right\|+\gamma_{i}\left\|A_{i}\left(x^{*}\right)\right\| \leq \gamma_{i} \frac{2}{1-\lambda_{i}}\left\|x-x^{*}\right\|
$$

and $\sum_{i=1}^{\infty} \gamma_{i} \frac{2}{1-\lambda_{i}}=\gamma<+\infty$, the mapping $A$ is well defined, and $\sum_{i=1}^{\infty} \gamma_{i} A_{i}(x)$ converges absolutely for each $x \in C$. It is easy to see that $A$ is Lipschitz continuous with the Lipschitz constant $L_{A}=\gamma$ and monotone.

Set

$$
G_{i}(u, v)=\left\langle\gamma_{i} A_{i}(u), v-u\right\rangle, \quad i \geq 1
$$

and

$$
G_{0}(u, v)=\left\langle A_{0}(u), v-u\right\rangle
$$

Then, problem (2.3) is equivalent to that: find $u_{\alpha} \in C$ such that

$$
G_{\alpha}\left(u_{\alpha}, v\right) \geq 0, \quad \forall v \in C,
$$

where

$$
G_{\alpha}(u, v)=\tilde{G}(u, v)+\alpha\langle u, v-u\rangle
$$

and

$$
\tilde{G}(u, v)=\sum_{i=0}^{\infty} G_{i}(u, v)=\left\langle A_{0}(u)+A(u), v-u\right\rangle .
$$

It is not difficult to verify that for each $i \geq 0, G_{i}(u, v)$ is a bifunction. Therefore, $\tilde{G}(u, v)(u, v)$ also is a bifunction, i.e., $\tilde{G}(u, v)(u, v)$ satisfies Assumption A. By using Lemma 2.2 with 
$(1 / r)=\alpha>0$ and $x=0$, we can conclude that problem (2.5) (consequently (2.3)) has a unique solution $u_{\alpha}$ for each $\alpha>0$.

(i) Next, we prove that

$$
\left\|u_{\alpha}\right\| \leq\|y\|, \quad \forall y \in \mathcal{S} .
$$

Since $y \in \mathcal{S}$, we have $A_{i}(y)=0, i \geq 0$. Thus,

$$
\sum_{i=0}^{\infty}\left\langle\gamma_{i} A_{i}\left(u_{\alpha}\right), y-u_{\alpha}\right\rangle+\alpha\left\langle u_{\alpha}, y-u_{\alpha}\right\rangle \geq 0, \quad \forall y \in \mathcal{S} .
$$

Since

$$
\left\langle\gamma_{i} A_{i}\left(u_{\alpha}\right), u_{\alpha}-y\right\rangle \geq 0, \quad \forall y \in \mathcal{S}, i \geq 0,
$$

from (2.7), follows (2.6). Then, there exists a subsequence $\left\{u_{\alpha_{k}}\right\}$ of $\left\{u_{\alpha}\right\}$ that converges weakly to some element $u^{*} \in H$. Now, we have to prove that $u^{*} \in \mathcal{S}$. The $\left(1-\lambda_{l}\right) / 2$-inverse strongly monotone property of $A_{l}$ implies that

$$
\begin{aligned}
0 & \leq \gamma_{l} \frac{1-\lambda_{l}}{2}\left\|A_{l}\left(u_{\alpha_{k}}\right)\right\|^{2} \\
& \leq\left\langle\gamma_{l} A_{l}\left(u_{\alpha_{k}}\right), u_{\alpha_{k}}-y\right\rangle \\
& \leq \sum_{i=1}^{\infty}\left\langle\gamma_{i} A_{i}\left(u_{\alpha_{k}}\right), u_{\alpha_{k}}-y\right\rangle \\
& \leq-\alpha_{k}\left\langle u_{\alpha_{k}}, u_{\alpha_{k}}-y\right\rangle \\
& \leq \alpha_{k}\left\langle y, y-u_{\alpha_{k}}\right\rangle .
\end{aligned}
$$

Therefore,

$$
\lim _{k \rightarrow \infty}\left\|A_{l}\left(u_{\alpha_{k}}\right)\right\|=0
$$

By virtue of Lemma 2.4, we have $u^{*} \in F\left(T_{l}\right)$. Since the closed convex set $\mathcal{S}$ has only one element with the minimal norm, using (2.6) and the weak convergence of $\left\{u_{\alpha}\right\}$, we can conclude that all the sequence $\left\{u_{\alpha}\right\}$ converges strongly to $u^{*}$ as $\alpha \rightarrow 0$.

(ii) By virtue of (2.4), (2.5) and the monotone property of $A_{i}$, we obtain

$$
\alpha\left\langle u_{\alpha}, u_{\beta}-u_{\alpha}\right\rangle+\beta\left\langle u_{\beta}, u_{\alpha}-u_{\beta}\right\rangle \geq 0
$$

or

$$
\left\|u_{\alpha}-u_{\beta}\right\| \leq \frac{|\alpha-\beta|}{\alpha}\left\|u_{\beta}\right\| \leq \frac{|\alpha-\beta|}{\alpha}\left\|u^{*}\right\|
$$

for each $\alpha, \beta>0$. This completes the proof.

Remark Obviously, if $u_{\alpha_{k}} \rightarrow \tilde{u}$, where $u_{\alpha_{k}}$ is the solution of (2.4) with $\alpha=\alpha_{k} \rightarrow 0$, as $k \rightarrow+\infty$, then $\mathcal{S} \neq \emptyset$. 
Theorem 2.6 Let $C$ be a nonempty closed convex subset of a real Hilbert space H. Let $G: C \times C \rightarrow(-\infty,+\infty)$ be a bifunction satisfying (A1)-(A4), and let $\left\{T_{i}\right\}_{i=1}^{\infty}$ be a sequence of nonself $\lambda_{i}$-strictly pseudocontractive mappings from $C$ into $H$ such that

$$
\mathcal{S}=\bigcap_{i=1}^{\infty} F\left(T_{i}\right) \cap \mathrm{EP}(G) \neq \emptyset .
$$

Assume that $\left\{\gamma_{i}\right\}$ satisfies condition (2.2), and $\alpha_{n}, \beta_{n}$ satisfy the following conditions:

$$
\begin{aligned}
& \alpha_{n}, \beta_{n}>0, \quad \lim _{n \rightarrow \infty} \alpha_{n}=0, \quad \lim _{n \rightarrow \infty} \frac{\left|\alpha_{n}-\alpha_{n+1}\right|}{\alpha_{n}^{2} \beta_{n}}=0, \\
& \sum_{n=0}^{\infty} \alpha_{n} \beta_{n}=\infty, \quad \varlimsup_{n \rightarrow \infty} \beta_{n} \frac{\left(2+\gamma+\alpha_{n}\right)^{2}}{\alpha_{n}}<1 .
\end{aligned}
$$

Then the sequence $\left\{z_{n}\right\}$ given by (2.1) converges strongly to $u^{*} \in \mathcal{S}$, that is,

$$
\lim _{n \rightarrow \infty} z_{n}=u^{*} \in \mathcal{S}
$$

Proof Clearly, iteration $\left\{z_{n}\right\}$ in (2.1) has the form

$$
z_{n+1}=P_{C}\left(z_{n}-\beta_{n}\left[\sum_{i=0}^{\infty} \gamma_{i} A_{i}\left(z_{n}\right)+\alpha_{n} z_{n}\right]\right), \quad z_{0} \in C, n \geq 0,
$$

where $\gamma_{0}=1$.

Let $u_{n}$ be the solution of (2.3) when $\alpha=\alpha_{n}$. Then

$$
u_{n}=P_{C}\left(u_{n}-\beta_{n}\left[\sum_{i=0}^{\infty} \gamma_{i} A_{i}\left(u_{n}\right)+\alpha_{n} u_{n}\right]\right) \text {. }
$$

Set $\Delta_{n}=\left\|z_{n}-u_{n}\right\|$. Obviously,

$$
\Delta_{n+1}=\left\|z_{n+1}-u_{n+1}\right\| \leq\left\|z_{n+1}-u_{n}\right\|+\left\|u_{n+1}-u_{n}\right\| .
$$

From the nonexpansive property of $P_{C}$, the monotone and Lipschitz continuous properties of $A_{i}, i \geq 0,(2.8)$, and (2.9), we have

$$
\left\|z_{n+1}-u_{n}\right\| \leq\left\|z_{n}-u_{n}-\beta_{n}\left[\sum_{i=0}^{\infty} \gamma_{i}\left(A_{i}\left(z_{n}\right)-A_{i}\left(u_{n}\right)\right)+\alpha_{n}\left(z_{n}-u_{n}\right)\right]\right\| \text {, }
$$

and

$$
\begin{aligned}
& \left\|z_{n}-u_{n}-\beta_{n}\left[\sum_{i=0}^{\infty} \gamma_{i}\left(A_{i}\left(z_{n}\right)-A_{i}\left(u_{n}\right)\right)+\alpha_{n}\left(z_{n}-u_{n}\right)\right]\right\|^{2} \\
& =\left\|z_{n}-u_{n}\right\|^{2}+\beta_{n}^{2}\left\|\left[\sum_{i=1}^{\infty} \gamma_{i}\left(A_{i}\left(z_{n}\right)-A_{i}\left(u_{n}\right)\right)+\alpha_{n}\left(z_{n}-u_{n}\right)\right]\right\|^{2}
\end{aligned}
$$




$$
\begin{aligned}
& -2 \beta_{n}\left\langle\sum_{i=0}^{\infty} \gamma_{i}\left(A_{i}\left(z_{n}\right)-A_{i}\left(u_{n}\right)\right)+\alpha_{n}\left(z_{n}-u_{n}\right), z_{n}-u_{n}\right\rangle \\
\leq & \left\|z_{n}-u_{n}\right\|^{2}\left[1-2 \beta_{n} \alpha_{n}+\beta_{n}^{2}\left(2+\sum_{i=1}^{\infty} \gamma_{i} \frac{2}{1-\lambda_{i}}+\alpha_{n}\right)^{2}\right] .
\end{aligned}
$$

Thus,

$$
\begin{aligned}
\left\|z_{n+1}-u_{n}\right\| & \leq \Delta_{n}\left(1-2 \beta_{n} \alpha_{n}+\beta_{n}^{2}\left(2+\gamma+\alpha_{n}\right)^{2}\right)^{1 / 2} \\
& \leq \Delta_{n}\left(1-\beta_{n} \alpha_{n}\right)^{1 / 2} \\
& \leq \Delta_{n}\left(1-\frac{1}{2} \beta_{n} \alpha_{n}\right) .
\end{aligned}
$$

Set

$$
\begin{aligned}
b_{n} & =\frac{1}{2} \alpha_{n} \beta_{n}, \\
c_{n} & =\frac{\alpha_{n}-\alpha_{n+1}}{\alpha_{n}}\left\|u^{*}\right\| .
\end{aligned}
$$

It is not difficult to check that $b_{n}$ and $c_{n}$ satisfy the conditions in Lemma 2.3 for sufficiently large $n$. Hence, $\lim _{n \rightarrow+\infty} \Delta_{n}^{2}=0$. Since $\lim _{n \rightarrow \infty} u_{n}=u^{*}$, we have

$$
\lim _{n \rightarrow \infty} z_{n}=u^{*} \in \mathcal{S}
$$

This completes the proof.

Remark The sequences $\alpha_{n}=(1+n)^{-p}, 0<p<1 / 2$, and $\beta_{n}=\gamma_{0} \alpha_{n}$ with

$$
0<\gamma_{0}<\frac{1}{\left(2+\gamma+\alpha_{0}\right)^{2}}
$$

satisfy all the necessary conditions in Theorem 2.6.

\section{Application}

In this section, we show that algorithm (2.1) can be applied to find an element

$$
u^{*} \in \mathcal{S} \cap \operatorname{VI}\left(C, A^{0}\right),
$$

where $\operatorname{VI}\left(C, A^{0}\right)$ is the set of solutions of the following variational inequality problem:

$$
\left\langle A^{0}(u), v-u\right\rangle \geq 0, \quad \forall v \in C, u \in C,
$$

involving a monotone hemicontinuous mapping $A^{0}$. If $A^{0}$ is a $\lambda$-inverse strongly monotone mapping, and $\left\{T_{i}\right\}_{i \geq 1}$ is a countably infinite family of nonexpansive self mappings in $C$, then problem (3.1) is recently studied in [40] and [41].

Let $A^{0}$ be a monotone hemicontinuous mapping. Then it is easy to see that $G^{0}(u, v)$ := $\left\langle A^{0}(u), v-u\right\rangle$ is a bifunction, i.e., $G^{0}(u, v)$ satisfies Assumption A. Using Lemma 2.2, we 
construct a nonexpansive mapping $T^{0}: H \rightarrow C$ such that

$$
T^{0}(x):=\left\{z \in C: G^{0}(z, v)+\langle z-x, v-z\rangle \geq 0 \forall v \in C\right\} .
$$

Then, $F\left(T^{0}\right)=V I\left(C, A^{0}\right)$. So, $T^{0}$ as $T_{0}$ are nonexpansive. Consequently, both mappings $T^{0}$ and $T_{0}$ are (1/2)-strictly pseudocontractive. Thus, the mapping $I-T^{0}$ is also Lipschitz continuous with the Lipschitz constant $L=2$. Then, algorithm (2.1) has the form:

Let $z_{0}$ be an arbitrary element in a Hilbert space $H$, the sequence of iteration $\left\{z_{n}\right\}$ is defined by

$$
\left\{\begin{aligned}
u_{n} & \in C: G\left(u_{n}, y\right)+\left\langle u_{n}-z_{n}, y-u_{n}\right\rangle \geq 0, \quad \forall y \in C, \\
u_{n}^{0} \in C: G^{0}\left(u_{n}^{0}, y\right)+\left\langle u_{n}^{0}-z_{n}, y-u_{n}^{0}\right\rangle \geq 0, \quad \forall y \in C, & \\
z_{n+1} & =P_{C}\left(z_{n}-\beta_{n}\left[z_{n}-u_{n}+z_{n}-u_{n}^{0}+\sum_{i=1}^{\infty} \gamma_{i} A_{i}\left(z_{n}\right)+\alpha_{n} z_{n}\right]\right) \\
& =P_{C}\left(z_{n}-\beta_{n}\left[\sum_{i=1}^{\infty} \gamma_{i} A_{i}\left(z_{n}\right)+\left(2+\alpha_{n}\right) z_{n}-u_{n}-u_{n}^{0}\right]\right), \quad n \geq 0 .
\end{aligned}\right.
$$

Theorem 3.1 Let $C$ be a nonempty closed convex subset of a real Hilbert space H. Let G : $C \times C \rightarrow(-\infty,+\infty)$ be a bifunction satisfying (A1)-(A4), let $\left\{T_{i}\right\}_{i=1}^{\infty}$ be a sequence of nonself $\lambda_{i}$-strictly pseudocontractive mappings from $C$ into $H$, and let $A^{0}$ be a hemicontinuous monotone mapping from $C$ into $H$ such that

$$
\bigcap_{i=1}^{\infty} F\left(T_{i}\right) \cap \mathrm{EP}(G) \cap V I\left(C, A^{0}\right) \neq \emptyset .
$$

Assume that $\left\{\gamma_{i}\right\}$ satisfies condition (2.2), and $\alpha_{n}, \beta_{n}$ satisfy the following conditions:

$$
\begin{aligned}
& \alpha_{n}, \beta_{n}>0, \quad \lim _{n \rightarrow \infty} \alpha_{n}=0, \quad \lim _{n \rightarrow \infty} \frac{\left|\alpha_{n}-\alpha_{n+1}\right|}{\alpha_{n}^{2} \beta_{n}}=0, \\
& \sum_{n=0}^{\infty} \alpha_{n} \beta_{n}=\infty, \quad \varlimsup_{n \rightarrow \infty} \beta_{n} \frac{\left(4+\gamma+\alpha_{n}\right)^{2}}{\alpha_{n}}<1 .
\end{aligned}
$$

Then

$$
\lim _{n \rightarrow \infty} z_{n}=u^{*} \in \bigcap_{i=1}^{\infty} F\left(T_{i}\right) \cap \operatorname{EP}(G) \cap V I\left(C, A^{0}\right),
$$

where $\left\{z_{n}\right\}$ is defined by (3.3).

\section{Competing interests}

The authors declare that they have no competing interests.

\section{Authors' contributions}

The main idea of this paper was proposed by JKK. JKK and NB prepared the manuscript initially and performed all the steps of proof in this research. All authors read and approved the final manuscript.

\section{Author details}

'Department of Mathematics, Kyungnam University, Changwon, Gyeongnam 631-701, Korea. ${ }^{2}$ Vietnamese Academy of Science and Technology, Institute of Information Technology, 18, Hoang Quoc Viet, q. Cau Giay, Hanoi, Vietnam. 


\section{Acknowledgements}

This work was supported by the Basic Science Research Program through the National Research Foundation (NRF) Grant funded by Ministry of Education of the Republic of Korea (2013R1A1A2054617).

Received: 13 April 2013 Accepted: 16 September 2013 Published: 08 Nov 2013

\section{References}

1. Browder, FE, Petryshyn, WV: Construction of fixed points of nonlinear mappings in Hilbert spaces. J. Math. Anal. Appl. 20, 197-228 (1967)

2. Takahashi, W, Toyota, M: Weak convergence theorems for nonexpansive mappings and monotone mappings. J. Optim. Theory Appl. 118, 417-428 (2003)

3. Blum, E, Oettli, W: From optimization and variational inequalities to equilibrium problems. Math. Stud. 63, 123-145 (1994)

4. Oettli, W: A remark on vector-valued equilibria and generalized monotonicity. Acta Math. Vietnam. 22, $215-221$ (1997)

5. Göpfert, A, Riahi, H, Tammer, C, Zalinescu, C: Variational Methods in Partially Ordered Spaces. Springer, New York (2003)

6. Chadli, O, Schaible, S, Yao, JC: Regularized equilibrium problems with an application to noncoercive hemivariational inequalities. J. Optim. Theory Appl. 121, 571-596 (2004)

7. Combettes, PL, Hirstoaga, SA: Equilibrium programming in Hilbert spaces. J. Nonlinear Convex Anal. 6(1), 117-136 (2005)

8. Konnov, IV, Pinyagina, OV: D-gap functions and descent methods for a class of monotone equilibrium problems. Lobachevskii J. Math. 13, 57-65 (2003)

9. Stukalov, AC: Regularization extragradient method for solving equilibrium programming problems in Hilbert spaces. Ž. Vyčisl. Mat. Mat. Fiz. 45(9), 1538-1554 (2005)

10. Kim, JK, Tuyen, TM: Regularization proximal point algorithm for finding a common fixed point of a finite family of nonexpansive mappings in Banach spaces. Fixed Point Theory Appl. 2011(52), 1-10 (2011). doi:10.1186/1687-1812-2011-52

11. Konnov, IV, Pinyagina, OV: D-gap functions for a class of monotone equilibrium problems in Banach spaces. Comput. Methods Appl. Math. 3, 274-286 (2003)

12. Mastroeni, G: Gap functions for equilibrium problems. J. Glob. Optim. 27, 411-426 (2003)

13. Anh, PN, Kim, JK: An interior proximal cutting hyperplane method for equilibrium problems. J. Inequal. Appl. 2012, 99 (2012). doi:10.1186/1029-242X-2012-99

14. Antipin, AS: Equilibrium programming: gradient methods. Autom. Remote Control 58, 1337-1347 (1997)

15. Antipin, AS: Equilibrium programming: proximal methods. Ž. Vyčisl. Mat. Mat. Fiz. 37, 1327-1339 (1997) Translation in Comput. Math. Math. Phys. 37, 1285-1296 (1997)

16. Antipin, AS: Solution methods for variational inequalities with coupled constraints. Comput. Math. Math. Phys. 40 1239-1254 (2000) Translated from Zh. Vychisl. Mat. Mat. Fiz. 40, 1291-1307 (2000)

17. Antipin, AS: Solving variational inequalities with coupling constraints with the use of differential equations. Differ. Equ. 36, 1587-1596 (2000) Translated from Differ. Uravn. 36, 1443-1451 (2000)

18. Bounkhel, M, Al-Senan, BR: An iterative method for nonconvex equilibrium problems. J. Inequal. Pure Appl. Math. 7(2), Article ID 75 (2006)

19. Buong, N: Approximation methods for equilibrium problems and common solution for a finite family of inverse-strongly monotone problems in Hilbert spaces. Appl. Math. Sci. 2, 735-746 (2008)

20. Chadli, O, Konnov, IV, Yao, JC: Descent methods for equilibrium problems in Banach spaces. Comput. Math. Appl. 48, 609-616 (2004)

21. Mastroeni, G: On auxiliary principle for equilibrium problems, Technical Report of the Department of Mathematics of Pisa University, Italy 3.244.1258 (2000)

22. Moudafi, A: Second-order differential proximal methods for equilibrium problems. J. Inequal. Pure Appl. Math. 4(1) Article ID 18 (2003)

23. Moudafi, A, Théra, M: Proximal and Dynamical Approaches to Equilibrium Problems. Lecture Notes in Econom. and Math. Systems, vol. 477, pp. 187-201. Springer, Berlin (1999)

24. Noor, MA, Noor, Kl: On equilibrium problems. Appl. Math. E-Notes 4, 125-132 (2004)

25. Kim, JK, Nam, YM, Sim, JY: Convergence theorem of implicit iterative sequences for a finite family of asymptotically quasi-nonexpansive type mappings. Nonlinear Anal. TMA 71(12), 2839-2848 (2009). doi:10.1016/j.na.2009.06.090

26. Kim, JK, Cho, SY, Qin, X: Some results on generalized equilibrium problems involving strictly pseudocontractive mappings. Acta Math. Sci. 31(5), 2041-2057 (2011)

27. Kim, JK: Strong convergence theorems by hybrid projection methods for equilibrium problems and fixed point problems of the asymptotically quasi-nonexpansive mappings. Fixed Point Theory Appl. (2011). doi:10.1186/1687-1812-2011-10

28. Kim, JK, Buong, N: An iterative method for common solution of a system of equilibrium problems in Hilbert spaces. Fixed Point Theory Appl. 2011, Article ID 780764 (2011). doi:10.1155/2011/780764

29. Kim, JK, Buong, N: Regularization inertial proximal point algorithm for monotone hemicontinuous mappings and inverse strongly monotone mappings in Hilbert spaces. J. Inequal. Appl. 2010, Article ID 451916 (2010) doi:10.1155/2010/451916

30. Kim, JK, Anh, PN, Nam, YM: Strong convergence of an extended extragradient method for equilibrium problems and fixed point problems. J. Korean Math. Soc. 49(1), 187-200 (2012)

31. Marino, G, Xu, HK: Weak and strong convergence theorems for strict pseudo-contractions in Hilbert spaces. J. Math Anal. Appl. 329(2), 336-346 (2007)

32. Wang, G, Peng, J, Lee, HJ: Implicit iteration process with mean errors for common fixed point of a family of strictly pseudocontractive maps. Int. J. Math. Anal. 1, 89-99 (2007)

33. Takahashi, S, Takahashi, W: Viscosity approximation methods for equilibrium problems and fixed point problems in Hilbert spaces. J. Math. Anal. Appl. 331, 506-515 (2007) 
34. Alvarez, F, Attouch, $\mathrm{H}$ : An inertial proximal method for maximal monotone operators via discretization of a nonlinear oscillator with damping. Set-Valued Anal. 9, 3-11 (2001)

35. Maingé, PE: Approximation methods for common fixed points of nonexpansive mappings in Hilbert spaces. J. Math. Anal. Appl. 325, 469-479 (2007)

36. Ceng, LC, Yao, JC: Hybrid viscosity approximation schemes for equilibrium problems and fixed point problems of infinitely many nonexpansive mappings. Appl. Math. Comput. 198, 729-741 (2008)

37. Vasin, W, Ageev, AL: Incorrect Problems with Priori Information. Nauka, Ekaterenburg (1993)

38. Osilike, MO, Udomene, A: Demiclosedness principle and convergence theorems for strictly pseudocontractive mappings. J. Math. Anal. Appl. 256, 431-445 (2001)

39. Li, G, Kim, JK: Demiclosedness principle and asymptotic behavior for nonexpansive mappings in metric spaces. Appl. Math. Lett. 14(5), 645-649 (2001)

40. Wangkeeree, R: An extragradient approximation method for equilibrium problems and fixed point problems of a countable family of nonexpansive mappings. Fixed Point Theory Appl. 2008, Article ID 134148 (2008)

41. Yao, Y, Liou, YC, Yao, JC: A new hybrid iterative algorithm for fixed point problems, variational inequality problems, and mixed equilibrium problems. Fixed Point Theory Appl. 2008, Article ID 417089 (2008)

10.1186/1687-1812-2013-286

Cite this article as: Kim and Buong: A new iterative method for equilibrium problems and fixed point problems for infinite family of nonself strictly pseudocontractive mappings. Fixed Point Theory and Applications 2013, 2013:286

\section{Submit your manuscript to a SpringerOpen ${ }^{\circ}$ journal and benefit from:}

- Convenient online submission

- Rigorous peer review

- Immediate publication on acceptance

- Open access: articles freely available online

- High visibility within the field

- Retaining the copyright to your article 